\title{
Effects of temperature and pH on xylitol recovery from oil palm empty fruit bunch hydrolysate by Candida tropicalis
}

\begin{abstract}
Oil Palm Empty Fruit Bunch (OPEFB) is composed of pentose that can be used as a raw material for the production of xylitol, a potential application in the food and medical areas. The effects of temperature and $\mathrm{pH}$ on xylitol bioconversion by yeast $\mathrm{sp}$. Candida tropicalis were investigated. The optimum $\mathrm{pH}$ resulted to be in the range of 2-4. The percentage of xylose consumed for xylitol production progressively increased with $\mathrm{pH}$, whereas those associated to both biomass growth and catabolic reaction through the TCA cycle decreased, reaching nearly constant values at $\mathrm{pH}$ 4. The optimum temperature range for xylitol production was $30-35^{\circ} \mathrm{C}$. Xylitol formation became the most significant activity at $20^{\circ} \mathrm{C}$, further increased up to $30-35^{\circ} \mathrm{C}$ and then decreased over $40^{\circ} \mathrm{C}$. The results collected at variable temperature were finally used for estimation of the parameters of the fermentation system.
\end{abstract}

Keyword: Xylose; Xylitol; Oil palm empty fruit bunch; Candida tropicalis 